\title{
Early surgical exposure for medical students: Efficacy and effect on choice of electives
}

\author{
Connor McGuire, BSc, MHSc, ${ }^{3}$ Todd Dow, BSc,' Emma Crawley, BSc, ' Kit Moran, \\ BSc, MSc,' Dafydd Davies, MD, MPhil, FRCSC ${ }^{1,2}$ \\ I. Faculty of Medicine, Dalhousie University, Halifax, Nova Scotia, Canada \\ 2. Division of Pediatric General \& Thoracic Surgery, Department of Surgery, Halifax, Nova Scotia, Canada \\ 3. Division of Plastic Surgery, Department of Surgery, Halifax, Nova Scotia, Canada
}

\begin{abstract}
Background: The number of students applying to surgical residency programs is declining. The reasons are multifactorial, however early exposure has been shown to increase application rates and decrease residency attrition rates. The objective of this study is to evaluate the Surgical Exploration and Discovery (SEAD) program, an early surgical exposure program, on its efficacy and influence on medical school electives. Methods: Two online surveys were distributed to participants of the SEAD program from 2016-2017. The surveys addressed demographics and prior surgical exposure, efficacy of the program, and the role of SEAD on influencing choice of electives. The Likert scale was used to measure responses along with multiple-choice questions. Univariate descriptive statistics were completed on all variables. Results: All participants $(n=36,100 \%$ response rate) reported that SEAD made them more likely to enter a surgical career (Mean: 4.I out of 5, SD: 0.8), helped narrow down career options (Mean: 4.0, SD: 0.9), and improved comfort in the OR environment (Mean: 4.7, SD; 0.5). The majority of students were planning to, or had completed at least one surgical elective in second year (72.2\%) and felt that the program will influence their choice of electives in fourth year (Mean: 4.0, SD: 0.6). Conclusion:The SEAD program is an effective method to help students make career decisions, offer early surgical exposure, and help with choice of medical electives. With a lack of early surgical exposure, and declining interest in surgical programs the SEAD program is a valuable addition to medical school education.
\end{abstract}

\section{Introduction}

Research has shown that the number of North American medical students applying to surgical residency programs has been declining over the past two decades $^{1-5}$. This unsustainable trend has led to concern among surgical program directors ${ }^{4,6,7}$. With an aging population, a decrease in the quantity of applicants to surgical residency positions is concerning.,8 Equally concerning is the evident declining match rate and attrition rate of several surgical specialties, such as general surgery ${ }^{9,10}$. This pattern has the potential to lead to "short-handed" programs that are not able to supply the same quality of service to a growing population or education to those residents remaining.

While the reasons for the declining interest in surgical residency programs are multifactorial, introducing role models and exposure to the operating room early in medical education have been identified as factors that increase interest in a surgical career ${ }^{2,4,6,8,11-}$ ${ }^{13}$.These factors support the idea that early surgical exposure to pre-clerkship medical students aids in their career decision-making. Specifically, mentorship has been reported as being one of the strongest influences on a medical student's career decision ${ }^{14}$. Meyer et al. suggested that the lack of a positive surgical role model in the pre-clerkship years accounted for $80 \%$ of students' negative views of surgery ${ }^{15}$.
Changes to medical education that encourage the importance of primary care and early career choices have inadvertently affected the field of surgical specialties ${ }^{1,16}$. Several studies have reported that majority (59-66\%) of medical students predict their career specialty prior to clerkship ${ }^{18,19}$. Furthermore, evidence suggests that the amount of exposure to a medical specialty correlates with the application rates of that specialty ${ }^{20}$. However, the majority of North American undergraduate medical students receive surgical exposure solely during their clerkship years ${ }^{21,22}$. One study demonstrated that a nearly five-fold increase was recorded in the number of medical students considering a surgical career based on their clerkship rotation experience alone, much of which was attributable to operating room exposure and resident and faculty interaction ${ }^{2}$.Two studies have demonstrated that direct participation in surgical procedures prior to clerkship was effective in increasing interest in a surgical career ${ }^{19,23}$. This suggests that declining interest among medical students and growing attrition among residents could be attributed to the lack of surgical exposure to pre-clerkship medical students. The 2004 American Surgical Association Blue Ribbon Committee Report on Surgical Education outlined this issue when they asked that, "surgical faculty and residents must become more involved in undergraduate medical education to develop and sustain in medical 
students an interest in a career in surgery"24. The Surgical Exploration and Discovery (SEAD) program has attempted to address this inadequacy by providing a wide breadth of exposure to many surgical specialties early in pre-clerkship.

The SEAD program was designed with the goal of increasing surgical exposure to pre-clerkship undergraduate medical students. The program, which was initiated at the University of Toronto in 2012, is a structured surgical program where first year medical students dedicate two weeks of their summer to surgical skills workshops, half-day electives in the operating room and seminars that focus on surgical lifestyle, research and specialties $^{25}$. During the 2015-2016 school year this program extended to Dalhousie University. The program followed the same structure as introduced at The University of Toronto, with the goal of strengthening career-minded decisions related to the field of surgery through early surgical exposure. The program has allowed students the opportunity to not only identify specialties of interest but to also rule out surgical specialties. In doing so, SEAD provides students with the opportunity to better prepare for clerkship as well as their elective choices moving forward.

The purpose of this study is to evaluate the efficacy of the Surgical Exploration and Discovery (SEAD) Program at Dalhousie Medical School and its influence on elective choices in the second and fourth year of medical school.

\section{Methods}

Two online surveys were distributed to all medical students who participated in the SEAD program from 2016-2017 via SurveyMonkey software (Survey Monkey Inc., San Mateo, CA). A total of 36 students were invited to complete the survey, as there were two years of programming and 18 students per cohort. There were no inclusion or exclusion criteria. A cover letter informed participants about the goals of the surveys, eligibility criteria and informed consent. Approval for this study was obtained through the Nova Scotia Health Authority research ethics board (File number 1088203).

The surveys were initially developed as quality control initiatives and to determine the effect of the SEAD program on choice of electives. The surveys went through a series of revisions by three medical students (C.M, T.D, and K.M.) and a staff surgeon (D.D.) prior to sending the survey to participating students. The study was then sent to the research ethics board for approval. A total of three reminders to complete the surveys were sent to participants.
The first "pre-program" survey addressed basic demographics, prior surgical exposure and efficacy of the SEAD program and was administered at the end of each respective SEAD program. This survey was administered to both cohorts of participants in 2016 and 2017. The second "post-program" survey addressed the role of the SEAD program on prospective elective choices and was developed and then administered following the second cohort of SEAD participants in 2017. The first cohort of SEAD participants did not complete this survey. By the time it had been disseminated, they had already completed their second-year electives. Survey questions were principally completed using a Likert scale (1-strongly disagree, 5-strongly agree) and using checkbox answers and multiple choice where required.

Univariate descriptive statistics were conducted on all variables to examine responses, distributions and potential errors. Continuous variables are presented as means and standard deviations (SD) and categorical variables are presented as counts and proportions. Statistical analyses were completed in SPSS Version 22.

\section{Results}

A total of $36 \mathrm{SEAD}$ program participants responded to the surveys (100\% response rate). Participants were more commonly male, between the ages of 25 and 26 years old and have a bachelor's degree (Table 1). Participants had generally observed between six and ten operating room (OR) half days and between one and two surgical specialties prior to beginning the SEAD program (Table 1).

Survey participants were strongly interested in a career in surgery prior to the SEAD program (Likert score of Mean: 4.2, SD: 0.7) and when asked about the efficacy of the program, students found the SEAD program helped them become more interested in pursuing a career in surgery (Mean: 4.1, SD: 0.8). They also agreed that the SEAD program was a positive addition to their medical education (Mean: 4.8, SD:0.4; Table 2).

The majority of Med 1 survey participants intended to complete their second-year elective in a surgical specialty (Mean: 3.9, SD: 0.9; Table 3). The majority of Med 2's completed their first semester elective in a surgical specialty (72.2\%), however approximately half did in second semester (55.6\%). Med 2's also agreed that they selected their clerkship track as a reflection of their desire to enter a surgical specialty (Mean: 4.2, SD: 1.3; Table 3).

All participants agreed that participating in the SEAD program helped them choose electives for second year (Mean: 4.1, SD: 0.7), and will likely help 
Table I. Demographic characteristics and prior surgical exposure of survey participants $(\mathrm{N}=36)$.

\begin{tabular}{|l|l|}
\hline Variable & Frequency \\
\hline $\mathrm{N}$ & 36 \\
\hline Gender & \\
Male & $23(63.9)$ \\
Female & $13(36.1)$ \\
\hline Age & \\
23-24 & $9(25.1)$ \\
$25-26$ & $15(41.7)$ \\
$27-28$ & $7(19.3)$ \\
$29-30$ & $4(11.1)$ \\
Skipped & $1(2.8)$ \\
Mean (SD) & $25.8(1.9)$ \\
\hline Year of study & \\
Med I & $18(50)$ \\
Med 2 & $18(50)$ \\
\hline Highest education received & \\
Bachelors & $20(55.6)$ \\
Masters & $16(44.4)$ \\
\hline OR half days observed prior to SEAD & \\
0-5 & $14(38.9)$ \\
6-I0 & $9(25)$ \\
II-I5 & $8(22.2)$ \\
>I5 & $4(11.1)$ \\
Skipped & $1(2.8)$ \\
Mean (SD) & $8.8(7.2)$ \\
\hline Surgical specialties observed prior to SEAD & \\
0 & $2(5.6)$ \\
I-2 & $16(44.4)$ \\
$3-4$ & $14(38.8)$ \\
$>4$ & $2(5.6)$ \\
Skipped & $2(5.6)$ \\
Mean (SD) & $2.5(1.6)$ \\
\hline
\end{tabular}

them choose their fourth year electives when the time comes (Mean: 4.0, SD: 0.6; Table 3). When asked about the specific components of the SEAD program and their respective influence on elective choices, participants found that observing in the operating room was the most beneficial (Mean: 4.5, SD: 0.6) followed by lunch time talks (Mean: 4.2, SD: 0.7), skills sessions (Mean: 4.1, SD: 0.8), and call night (Mean: 3.3, SD: 1.2; Table 3). The SEAD program, in general, had a significant influence on participants in terms of gaining and losing interest in specific surgical specialties, as demonstrated in Table 4.

\section{Discussion}

This study determined that the majority of student participants had limited surgical exposure prior to beginning the SEAD program. This was based on the student's self-reported number of surgical specialties observed and half days spent in the operating room prior to engaging in the SEAD program. Participants reported that the SEAD program made them more
Table 2. Survey responses from participants concerning efficacy of the SEAD program $(\mathrm{N}=36)$. All scores are based on a five-point Likert scale, where I-strongly disagree and 5 -strongly agree.

\begin{tabular}{|l|l|}
\hline & Mean (SD) \\
\hline $\begin{array}{l}\text { I was interested in a surgical career prior to } \\
\text { starting the SEAD program. }\end{array}$ & $4.2(0.7)$ \\
\hline $\begin{array}{l}\text { Completing the SEAD program has made me } \\
\text { more interested in pursuing a surgical career. }\end{array}$ & $4 . I(0.8)$ \\
\hline $\begin{array}{l}\text { Completing the SEAD program has helped me } \\
\text { narrow my options for a surgical career. }\end{array}$ & $4.0(0.9)$ \\
\hline $\begin{array}{l}\text { Overall, I feel that the SEAD program has } \\
\text { helped me to make decisions on my future } \\
\text { career. }\end{array}$ & $4.2(0.9)$ \\
\hline $\begin{array}{l}\text { Overall, I felt that my experiences during the } \\
\text { SEAD program have made me more comfort- } \\
\text { able in the operating room environment. }\end{array}$ & $4.7(0.5)$ \\
\hline $\begin{array}{l}\text { Overall, I felt that the residents and staff made } \\
\text { my experience in the operating room positive. }\end{array}$ & $4.5(0.6)$ \\
\hline $\begin{array}{l}\text { Overall, I feel that my experience during SEAD } \\
\text { program was positive. }\end{array}$ & $4.8(0.4)$ \\
\hline
\end{tabular}

Table 3. Survey responses from participants concerning choice of electives. All scores are based on a five-point Likert scale, where I-strongly disagree and 5-strongly agree.

\begin{tabular}{|c|c|}
\hline & Mean (SD) \\
\hline \multicolumn{2}{|l|}{ Med I Cohort $(\mathrm{N}=\mid 8)$} \\
\hline $\begin{array}{l}\text { Med I's: I intend to complete my second-year elec- } \\
\text { tive in a surgical specialty. }\end{array}$ & $3.9(0.9)$ \\
\hline $\begin{array}{l}\text { Med I's: In what specialty do you intend to complete } \\
\text { your second-year elective (count (percentage))? } \\
\text { Surgical } \\
\text { Medical } \\
\text { Unsure }\end{array}$ & $\begin{array}{l}\text { I3 (72.2) } \\
\text { I (5.6) } \\
4(22.2)\end{array}$ \\
\hline $\begin{array}{l}\text { Participating in the SEAD program has helped me } \\
\text { choose electives for second year. }\end{array}$ & $4.1(0.7)$ \\
\hline $\begin{array}{l}\text { Participating in the SEAD program will help my } \\
\text { future decisions on electives in fourth year. }\end{array}$ & $4.0(0.6)$ \\
\hline $\begin{array}{l}\text { Overall, I felt that the opportunity to observe in the } \\
\text { OR during SEAD was worthwhile in helping elective } \\
\text { choices. }\end{array}$ & $4.5(0.6)$ \\
\hline $\begin{array}{l}\text { Overall, I felt that the lunchtime talks during SEAD } \\
\text { were worthwhile in helping with elective choices. }\end{array}$ & $4.2(0.7)$ \\
\hline $\begin{array}{l}\text { Overall, I felt that the skills sessions during SEAD } \\
\text { were worthwhile in helping elective choices. }\end{array}$ & $4.1(0.8)$ \\
\hline \multicolumn{2}{|l|}{ Med 2 Cohort $(\mathrm{N}=18)$} \\
\hline $\begin{array}{l}\text { Med 2's: I completed my first semester second year } \\
\text { elective in a surgical speciality (count (percentage)). } \\
\text { Yes } \\
\text { No }\end{array}$ & $\begin{array}{l}\text { I3 (72.2) } \\
5(27.8)\end{array}$ \\
\hline $\begin{array}{l}\text { Med 2's: I completed my second semester second } \\
\text { year elective in a surgical speciality (count (percent- } \\
\text { age)). } \\
\text { Yes } \\
\text { No }\end{array}$ & $\begin{array}{l}10(55.6) \\
8(44.4)\end{array}$ \\
\hline $\begin{array}{l}\text { Med 2's: I chose my track selection in third year to } \\
\text { reflect my desire to enter a surgical speciality. }\end{array}$ & $4.2(1.3)$ \\
\hline
\end{tabular}


Table 4. Interest in specific surgical specialties before and after the SEAD program $(\mathrm{N}=36)$. *Pediatric orthopedics was only available to the second cohort of SEAD participants (Med I's).

\begin{tabular}{|c|c|c|c|c|c|}
\hline $\begin{array}{l}\text { Surgical Spe- } \\
\text { cialty }\end{array}$ & $\begin{array}{l}\text { Number before } \\
\text { SEAD }\end{array}$ & $\begin{array}{l}\text { Number after } \\
\text { SEAD }\end{array}$ & $\begin{array}{l}\text { Number that devel- } \\
\text { oped a new interest }\end{array}$ & $\begin{array}{l}\text { Number that } \\
\text { ruled out prior } \\
\text { interest }\end{array}$ & $\begin{array}{l}\text { Net change in num- } \\
\text { ber interested }\end{array}$ \\
\hline Otolaryngology & 18 & 23 & 9 & 4 & +5 \\
\hline Plastic surgery & 20 & 22 & 6 & 4 & +2 \\
\hline Thoracic surgery & 9 & II & 5 & 3 & +2 \\
\hline Vascular surgery & 17 & 18 & 7 & 6 & +1 \\
\hline $\begin{array}{l}\text { Pediatric general } \\
\text { surgery }\end{array}$ & 10 & 10 & 3 & 3 & 0 \\
\hline $\begin{array}{l}\text { Orthopedic } \\
\text { surgery }\end{array}$ & 9 & 7 & 1 & 3 & -2 \\
\hline $\begin{array}{l}\text { Pediatric ortho- } \\
\text { pedics* }\end{array}$ & 6 & 4 & 1 & 3 & -2 \\
\hline Cardiac surgery & 17 & 12 & 2 & 7 & -5 \\
\hline Neurosurgery & 14 & 4 & 0 & 10 & -10 \\
\hline General surgery & 23 & 13 & 0 & 10 & -10 \\
\hline Other specialties & 6 & 5 & 0 & $\mathrm{I}$ & -1 \\
\hline Median & 14 & 11 & 2 & 4 & -1 \\
\hline
\end{tabular}

likely to enter a surgical career, and that the program was a positive addition to their medical education that would benefit them in the future with respect to career minded decisions. Survey information indicated that the majority of participants are planning to, or have already, completed at least one surgical elective in their second year. Furthermore, SEAD student participants felt that their involvement with the program influenced their choice of electives in fourth year prior to residency. Participant's reported that the operating room component of the SEAD program was the most influential component.

To date, a number of studies have been completed on the other SEAD programs across Canada at the University of Ottawa and the University of Toronto. Our demographic information and prior surgical exposure variables are comparable with these previously published reports ${ }^{25-28}$. However, our participants were generally older, and a greater percentage had received a master's degree prior to participating in the SEAD program $(44.4 \% \text { compared to } 16.7 \%)^{26}$. In general, prior to participating in the SEAD program, participants had a low amount of surgical exposure (8.8 OR half days observed, and 2.5 surgical specialities observed). These findings are similar to other studies and likely reflect the inability to observe a wide range of surgical specialties in the first year of medical school ${ }^{25-28}$. Most medical schools across Canada do not have electives until second year, and it is increasingly difficult to coordinate observerships with specific surgeons. This is due to time constraints, conflicts with classes/ tutorials, and procedural hurdles with undergraduate medical education departments. The SEAD program allows students to observe upwards of ten surgical subspecialties within a two-week period. Consequently, this results in the student identifying new interests and filtering potential career paths in a short time frame $e^{25,26}$.

Prior studies have shown that before starting the SEAD program the majority of student participants are already interested in a surgical career, which is congruent with our results ${ }^{25-28}$. We found that the mean Likert scale value was 4.2 out of 5 (SD: 0.7) compared to 13 out of 18 students being "very interested" in a surgical career prior to the SEAD program in the cohort described by Gawad and colleagues ${ }^{25}$. What has not previously been demonstrated is that early exposure through a program such as SEAD improves comfort in the operating room environment. This has typically been perceived as a complex and sometimes challenging environment for medical students ${ }^{29}$. In addition, our study mirrored previous results in regard to narrowing career options and aiding with future career decisions ${ }^{25-28}$. These results are encouraging due to the deceasing application rates to surgical residency programs ${ }^{1,4}$. It is our hope that the SEAD program initiated at Dalhousie medical school will not only help increase the number of applications to surgical residency programs, but will also help to decrease attrition rates throughout residency by allowing students to make more informed career decisions prior to application. Future research will be necessary at the time of application and matching to residency to determine the influence of the SEAD program on these processes. It is our intent to engage in future discussions 
with students who have participated in the program to determine whether the SEAD program influenced their decision to apply and work as surgeons.

The influence of the SEAD program on the student's choice of electives in second and fourth year has largely been understudied. Electives are offered at varying times in Canada depending on the medical school and are a crucial step to solidifying interest in a career. Research has shown that students who complete early electives in any medical speciality, both surgical and medical, are more likely to pursue that specialty as a career ${ }^{4,11,30}$.We have demonstrated that the majority of SEAD participants intend to complete at least one second year elective in a surgical specialty, and felt that completing the SEAD program will help them to choose electives for both second and fourth year. Currently, it is difficult to assess whether or not students are choosing surgical electives based on their experience with the SEAD program, or due to their prior interest in a surgical career before participating in the program. Future studies may incorporate pre and post-SEAD surveys to limit bias in determining the influence of the SEAD program on the student's choice of electives.

Gawad and colleagues found that the operating room component of the SEAD program, compared to the lunchtime seminars and skills sessions, was the most beneficial component ${ }^{25}$. We were able to evaluate these components in terms of influence on student's choice of electives and found comparable results. However, the Dalhousie SEAD program also incorporated a call night, which was not found to be as helpful with elective choices (Mean: 3.3, SD: 1.2). This is likely due to the inherently variable experience a night on call may bring. During informal discussion with the students during the two-week period, many remarked how they either had a very positive experience on call or were simply not called in. It is difficult to predict which evenings may be busy and consequently, a beneficial and stimulating experience for the students. However, we believe that incorporating the call night component into the SEAD program can be a valuable experience, one that further demonstrates the true lifestyle of a surgeon and provides additional influential interaction with residents and faculty. We plan on trying to improve the call night experience in the future by refining which specialties are involved and speaking with attending physicians and residents to figure out which nights on call would be most beneficial.

The majority of participating students were able to gain interest in or rule out a surgical specialty over the course of the program. Lifestyle friendly specialties, like plastic surgery and otolaryngology gained interest, whereas specialties generally considered as having an inferior work life balance, like general surgery, lost interest. Interest in neurosurgery also decreased in our study population. Studies have revealed that medical students have shown an increased desire for work-life balance, citing factors like the length of residency training, job concerns, and the rates of mental illness as underlying concerns $\mathrm{s}^{31-33}$. Greene and colleagues found similar results when examining interest in surgical subspecialties before and after the SEAD program, however their results were not as robust due to a smaller sample size ${ }^{27}$. It will be important to determine if participation in SEAD negatively impacts applications to these specialties. It is our hope that the students who do apply to them will be better informed and prepared improving overall attrition even if application rates decline.

The benefit of the SEAD program on career-minded decisions, such as students identifying interest in a certain specialty, has been well described ${ }^{25-28}$. However, of equal or greater importance is the examination of students' loss of interest and the various avenues of discussion this allows for. These discussions could assist in identifying solutions as to how to attract students to specialties with declining application rates. One hypothesized reason for the substantial decrease of interest in specialties like general surgery and neurosurgery through the Dalhousie SEAD program is the fact that students largely interacted with residents from these specialties during the program. Whereas for a specialty like pediatric general surgery, they were able to interact with faculty, who would be more suitable for alleviating lifestyle related concerns. Research has shown that when a staff surgeon as opposed to a resident addresses concerns related to the work-life balance of a specialty, it has been found to positively influence opinions of that specialty ${ }^{19}$. In the future, SEAD programs may find it beneficial to focus on exposing students to a mixture of both staff and residents in all components of the program to promote an understanding of a surgical lifestyle.

The strengths of our study include a large sample size, high survey response rate, exposure to many components of a surgical practice, and the generalizability of the data to other SEAD programs across Canada. The weaknesses of our study include the use of subjective measures, the retrospective nature of the study, and the short follow-up. We acknowledge the need for long-term, prospective studies examining the efficacy of the program. Nevertheless, our study provides important data on an area of surgical education that increases interest in surgical careers and helps students with career-minded decisions early in medical school. 


\section{Conclusion}

The SEAD program is an effective method to help students make career decisions, offer early surgical exposure, and help with choice of medical electives. With a lack of early surgical exposure, and declining interest in surgical programs the SEAD program is a valuable addition to medical school education.

\section{Acknowledgements}

The authors are grateful to the Department of Surgery as a whole, as well as Brock Vair, MD, Liz Craig, Kathy Hartlen, Jennifer Hall, MD, Evelyn Sutton, MD, David Anderson, MD and the many other staff, faculty and administration for their constant support, advocacy and organizational assistance. Furthermore, SEAD at Dalhousie is a branch of SEAD, which was created by Nada Gawad, MD, with the support of James Rutka, MD, and the Department of Surgery at the University of Toronto.

\section{References}

1. Minor S, Poenaru D, Park J. A study of career choice patterns among Canadian medical students. Am J Surg. 2003;186(2): 182-188.

2. O’Herrin JK, Lewis BJ, Rikkers LF, Chen H. Why do students choose careers in surgery?. J Surg Research. 2004;119(2):124129.

3. Berman L, Rosenthal MS, Curry LA, Evans LV, Gusberg RJ. Attracting surgical clerks to surgical careers: role models, mentoring, and engagement in the operating room. J Am Col Surg. 2008;207(6):793-800.

4. Scott IM, Matejcek AN, Gowans MC, Wright BJ, Brenneis FR. Choosing a career in surgery: factors that influence Canadian medical students' interest in pursuing a surgical career. Can J Surg. 2008;51(5):371.

5. Cochran A, Paukert JL, Neumayer LA. Does a general surgery clerkship influence student perceptions of surgeons and surgical careers?. Surgery. 2003;134(2):153-157.

6. Dodson TF, Webb AL. Why do residents leave general surgery? The hidden problem in today's programs. Curr Surg. 2005;62(1) L:128-131.

7. Cofer JB, et al. Is the quality of surgical residency applicants deteriorating?. Am J Surg. 2001;181(1):44-49.

8. Azizzadeh A, et al. Factors influencing career choice among medical students interested in surgery. Curr Surg. 2003;60(2):210-213.

9. Bland KI, Isaacs G. Contemporary trends in student selection of medical specialties: the potential impact on general surgery. Arch Surg. 2002;137(3):259-267.

10. Gabram SG, Allen LW, Deckers PJ. Surgical residents in the 1990s: issues and concerns for men and women. Arch Surg. 1995;130(1):24-28.

11. Erzurum VZ, et al. What influences medical students' choice of surgical careers. Surg. 2000;128(2):253-256.

12. Glynn RW, Kerin MJ. Factors influencing medical students and junior doctors in choosing a career in surgery. The Surgeon. 2010;8(4):187-191.
13. Polk HC. The declining interest in surgical careers, the primary care mirage, and concerns about contemporary undergraduate surgical education. Am J Surg. 1999;178(3):177-179.

14. Wright S, Wong A, Newill C. The impact of role models on medical students. J Gen Int Med. 1997;12(1):53-56.

15. Meyer AA, Weiner TM. The generation gap: perspectives of a program director. Arch Surg.2004;137(3):268-270.

16. Resnick DK. Neuroscience education of undergraduate medical students. Part I: role of neurosurgeons as educators. J Neurosurg. 2000;92(4):637-641

17. Saleh M. Attracting the top medical students to a career in neurosurgery. Brit J Neurosurg. 2013;27(3):405-410.

18. Zeldow PB, Preston RC, Daugherty SR. The decision to enter a medical specialty: timing and stability. Med Ed. 1992;26(4):327332.

19. Kozar RA, et al. Brief intervention by surgeons can influence students toward a career in surgery. J Surg Research. 2003;111(1):166-169.

20. Bernstein J, DiCaprio MR, Mehta S. The relationship between required medical school instruction in musculoskeletal medicine and application rates to orthopaedic surgery residency programs. JBJS. 2004;86(10):2335-2338.

21. Al-Heeti KN, Nassar AK, DeCorby K, Winch J, Reid S. The effect of general surgery clerkship rotation on the attitude of medical students towards general surgery as a future career. J Surg Ed. 2012;69(4):544-549.

22. Cloyd J, et al. Operating room assist: surgical mentorship and operating room experience for preclerkship medical students. J Surg Ed. 2008;65(4):275-282.

23. Kirkham JC, et al. Medical student entry into general surgery increases with early exposure to surgery and to surgeons. Curr Surg. 2006;63(6):397-400.

24. Debas HT, et al. American surgical association blue ribbon committee report on surgical education: 2004. Ann Surg. 2005;241(1):1.

25. Gawad N, Moussa F, Christakis GT, Rutka JT. Planting the 'SEAD': Early comprehensive exposure to surgery for medical students. J Surg Ed. 2013;70(4):487-494.

26. Head L, et al. Growing the 'SEAD': Expansion of the Surgical Exploration and Discovery Program. J Surg Ed. 2016;73(1):102110 .

27. Greene B, Head L, Gawad N, Hamstra SJ, McLean L. Surgical exploration and discovery program: inaugural involvement of otolaryngology-head and neck surgery. J Otolaryn- Head \& Neck. 2015;44(1):3.

28. Zuccato JA, Kulkarni AV. The impact of early medical school surgical exposure on interest in neurosurgery. Can J Neuro Sci. 2015;43:410-416.

29. Curry SE, Cortland CI, Graham MJ. Role-modelling in the operating room: Medical student observations of exemplary behaviour. Med Ed. 2011;45:946-957.

30. Jordan J, Brown JB, Russell G. Choosing family medicine. What influences medical students? Can Fam Phys. 2003;49(9):11311137.

31. Brown AJ, Friendman AH. Challenges and opportunities for recruiting a new generation of neurosurgeons. Neurosurg. 2007;61:1314-1316.

32. Dorsey ER, Jarjoura D, Rutecki GW. Influence of controllable lifestyle on recent trends in specialty choice by US medical students. JAMA. 2003;290:1173-1178.

33. Ek EW, Ek ET, MacKay SD. Undergraduate experience of surgical teaching and its influence on career choice. ANZ J Surg. 2005;75:713-718 